\title{
ESTIMASI GERAK TRANSLASI AUTONOMOUS UNDERWATER VEHICLE DENGAN ENSEMBLE KALMAN FILTER (EnKF)
}

\author{
Teguh Herlambang ${ }^{1}$, Subchan ${ }^{2}$ \\ 1Program Studi Sistem Informasi, Fakultas Teknik \\ Universitas Nahdlatul Ulama Surabaya, Indonesia \\ e-mail : teguh@unusa.ac.id \\ ${ }^{2}$ Departemen Matematika, Fakultas Matematika, Komputasi dan Sains Data \\ Institut Teknologi Sepuluh Nopember, Indonesia \\ e-mail : subchan@matematika.its.ac.id \\ Diterima: 18 April 2018. Disetujui : 15 Juni 2018. Dipublikasikan : 29 Juni 2018 \\ (C)2018 -TESJ Fakultas Teknik Universitas Maarif Hasyim Latif. Ini adalah artikel dengan \\ akses terbuka di bawah lisensi CC BY 4.0 (https://creativecommons.org/licenses/by/4.0/)
}

\begin{abstract}
ABSTRAK
Penelitian dan pengembangan dari Autonomous Underwater Vehicle cukup banyak diantaranya terkait sistem kendali, navigasi dan hidrodinamika. Pada umunya persamaan gerak AUV adalah 6 derajat kebebasan/Degree of Freedom (DOF) yang terdiri dari gerak translasi (surge, sway, heave) dan gerak rotasi (roll, pitch, yaw). Pada paper ini dikembangkan metode estimasi gerak tranlasi dari ITSUNUSA AUV dengan metode Ensemble Kalman Filter. Pada paper ini juga dibandingkan berdasarakn pembangkian julah ensemble. Hasil simulasi menunjukkan bahwa yang terakurat adalah dengan membangkitkan 300 ensemble dengan error kecepatan untuk gerak surge adalah $0,082 \%$, gerak sway $0.498 \%$ dan gerak heave $0.26 \%$.
\end{abstract}

Kata kunci: auv, estimasi gerak, sistem navigasi, ensemble kalman filter

\section{PENDAHULUAN}

AUV dipekerjakan di bawah laut untuk penelitian di dasar laut dan beberapa industri terkait kelautan. Penelitian dan Pengembangan AUV cukup banyak diantaranya terkait sistem kendali, navigasi dan hidrodinamika. (T. Herlambang, Nurhadi, \& Subchan, 2014). AUV terdiri dari 6-DOF yang merupakan kombinasi dari gerak translasi (3-DOF) dan rotasi (3-DOF) (Oktafianto, Herlambang, Mardlijah, \& Nurhadi, 2016). Beberapa penelitian terkait sistem navigasi diantaranya adalah An dkk menjelaskan sistem navigasi AUV dengan metode heuristic fuzzy filtering dan Menggunakan Ocen Explorer AUV dengan panjang $7 \mathrm{ft}$ dan diameter $21 \mathrm{~cm}$, speed 3 knot (An, Healey, Park, \& Smith, 1997). Selanjutnya Kondo dan Ura menerapkan laser ranging system pada sistem navigasi AUV(Kondo \& Ura, 2004). Loebis dkk menggunakan metode Adaptive Kalman Filter dan Fuzzy Kalman Filter pada AUV (Loebis, Sutton, Chudley, \& Naeem, 2004). Repoulias dan Papadopoulos menggunakan trajectory tracking control pada lintasan memutar (Repoulias \& Papadopoulos, 2007). Sedangkan Ermayanti dkk menggunakan SEGOROGENI AUV dengan Fuzzy Kalman Filter (FKF) (Ermayanti, Apriliani, Nurhadi, \& Herlambang, 2016), dan Herlambang dkk menggunakan EnKF-SR pada model linier AUV SEGOROGENI (T. Herlambang, Djatmiko, \& Nurhadi, 2015).

Diantara metode-metode di atas, terdapat salah satu metode yang dapat digunakan untuk estimasi gerak AUV, adalah metode Ensemble Kalman Filter (EnKF). Metode EnKF digunakan untk estimasi lintasan AUV 6-DOF model linier (T. Herlambang, Djatmiko, \& Nurhadi, 2016), selain itu juga utk estimasi lintasan peluru kendali (Teguh Herlambang, 2017b), estimasi temperature uap pada steam drum boiler (T. Herlambang, Mufarrikoh, Karya, \& Rahmalia, 2018), Sehingga pada paper ini menggunakan metode EnKF untuk estimasi gerak translasi dari ITSUNUSA AUV. Pada paper ini membandingkan pembangkitan jumlah ensemble sejumlah 100, 200 dan 300 ensemble. Hasil simulasi menunjukkan bahwa yang terakurat adalah dengan membangkitkan 300 ensemble dengan error kecepatan untuk gerak surge adalah $0,082 \%$, gerak sway $0.498 \%$ dan gerak heave $0.26 \%$ atau denga kata lain tingkat akurasi dari metode EnKF adaah kurang lebih 99\%. 


\section{METODE PENELITIAN}

Metode penelitian ini dijelaskan diagram alir pada Gambar 1.

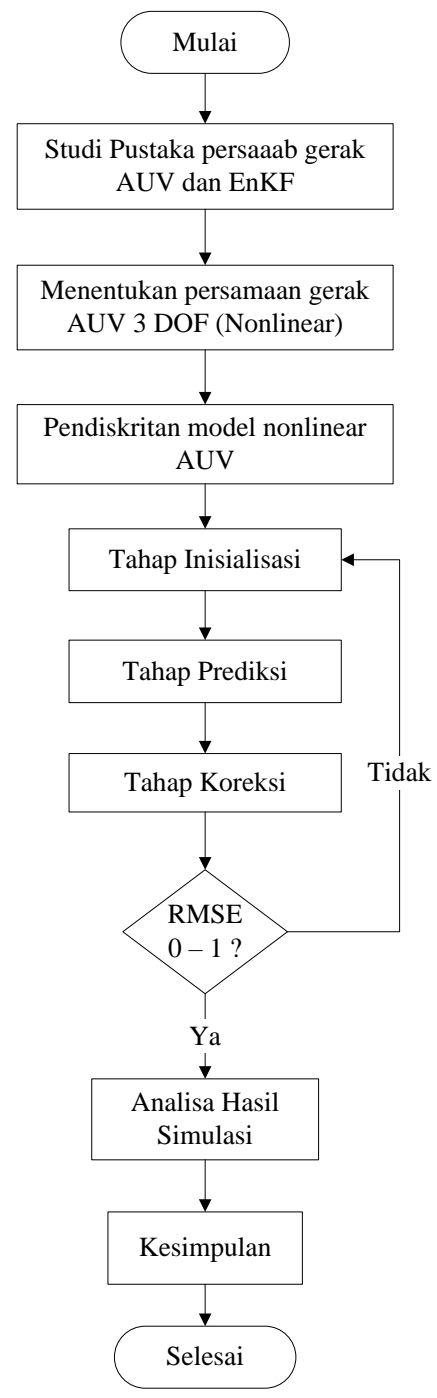

Gambar 1. Diagram alir

\section{HASIL DAN PEMBAHASAN}

Untuk menganalisa sistem AUV terdapat dua hal penting yang diperlukan, yaitu sistem sumbu yang terdiri dari Earth Fixed Frame (EFF) dan Body Fixed Frame (BFF) (Teguh Herlambang \& Nurhadi, 2017). Pada paper ini hanya menganalisa dari EFF saja, dimana EFF digunakan untuk menjelaskan posisi dan orientasi dari AUV, dimana posisi sumbu-x mengarah ke arah utara, sumbu-y ke arah timur dan sumbu-z ke arah pusat bumi (Teguh Herlambang, 2017a). Pada paper ini menggunakan persamaan gerak dalam 3-DOF yaitu surge, sway dan heave dengan mengabaikan gerak rotasi yaitu roll, pitch dan yaw. Berikut adalah persamaan gerak dalam 3-DOF: Surge:

$$
\dot{u}=\frac{X_{r e s}+u|u|+X_{\dot{u}} \dot{u}+X_{\text {prop }}}{m}
$$

Sway:

$$
\dot{v}=\frac{Y_{r e s}+Y_{|v| v} v|v|+Y_{\dot{v}} \dot{v}+Y_{u v} u v+Y_{u u \delta_{r}} u^{2} \delta_{r}}{m}
$$

Heave:

$$
\dot{w}=\frac{Z_{r e s}+Z_{|w| w} w|w|+Z_{\dot{w}} \dot{w}+Z_{u w} u w+Z_{u u \delta_{S}} u^{2} \delta_{s}}{m}
$$

Berikut adalah profil dan spesifikasi dari ITSUNUSA AUV pada Gambar 2 dan Tabel 1.

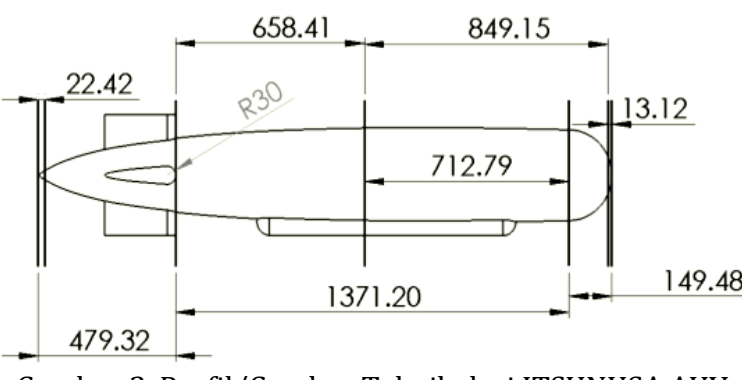

Gambar 2. Profil/Gambar Teknik dari ITSUNUSA AUV

Tabel 1. Spesifikasi dari ITSUNUSA AUV

\begin{tabular}{|l|l|}
\hline Weight & $16 \mathrm{Kg}$ \\
Overall Length & $2000 \mathrm{~mm}$ \\
Beam & $300 \mathrm{~mm}$ \\
Controller & Ardupilot Mega 2.0 \\
Communication & Wireless Xbee $2.4 \mathrm{GHz}$ \\
Camera & TTL Camera \\
Battery & Li-Pro 11,8 V \\
Propulsion & 12V motor DC \\
Propeller & 3 Blades OD : 40 mm \\
Speed & 1,94 knots $(1 \mathrm{~m} / \mathrm{s})$ \\
Operation Depth & $8 \mathrm{~m}$ \\
\hline
\end{tabular}

Sedangkan algoritma Ensemble Kalman Filter adalah sebagai berikut (T. Herlambang et al., 2016):

Model Sistem dan Model Pengukuran

$$
\begin{gathered}
x_{k+1}=f\left(x_{k}, u_{k}\right)+w_{k} \\
z_{k}=H x_{k}+v_{k} \\
w_{k} \sim N\left(0, Q_{k}\right), v_{k} \sim N\left(0, R_{k}\right)
\end{gathered}
$$

1. Inisialisasi

Bangkitkan $N$ ensemble sesuai estimasi awal $\bar{x}_{0}$ dengan

$$
x_{0, i}=\left[\begin{array}{llll}
x_{0,1} & x_{0,2} & \ldots & x_{0, N}
\end{array}\right]
$$

Tentukan nilai awal:

$$
\hat{x}_{0}=\frac{1}{N} \sum_{i=1}^{N} x_{0, i}
$$

2. Tahap Prediksi

$$
\hat{x}_{k, i}^{-}=f\left(\hat{x}_{k,-1, i}, u_{k-1, i}\right)+w_{k, i}
$$

Dimana

$$
w_{k, i}=N\left(0, Q_{k}\right)
$$

Estimasi : 


$$
\hat{x}_{k}^{-}=\frac{1}{N} \sum_{i=1}^{N} \hat{x}_{k, i}^{-}
$$

Kovarian Error :

$$
P_{k}^{-}=\frac{1}{N-1} \sum_{i=1}^{N}\left(\hat{x}_{k, i}^{-}-\hat{x}_{k}^{-}\right)\left(\hat{x}_{k, i}^{-}-\hat{x}_{k}^{-}\right)^{T}
$$

3. Tahap koreksi

$$
z_{k, i}=H x_{k, i}+v_{k, i} \text { dimana } v_{k, i} \sim N\left(0, R_{k}\right)
$$

Kalman gain :

$$
K_{k}=P_{k}^{-} H^{T}\left(H P_{k}^{-} H^{T}+R_{k}\right)^{-1}
$$

Estimasi :

$$
\begin{gathered}
\hat{x}_{k, i}=\hat{x}_{k, i}^{-}+K_{k}\left(z_{k, i}-H \hat{x}_{k, i}^{-}\right) \\
\hat{x}_{k}=\frac{1}{N} \sum_{i=1}^{N} \hat{x}_{k, i}
\end{gathered}
$$

Kovarian error:

$$
P_{k}=\left[I-K_{k} H\right] P_{k}^{-}
$$

Dari persamaan gerak AUV pada persamaan (1)-(3) didiskritisasi lalu diinputkan dalam algoritma EnKF dengan membangkitkan 100, 200 dan 300 ensemble, Perbandingan jumlah ensemble menunjukkan bahwa dengan membangkitkan ensemble sejumlah 300 lebih baik daripada 100 dan 200 ensemble.

Simulasi ini menggunakan $\Delta t=0,1$ serta dengan membangkitkan ensemble sejumlah 100 , 200 dan 300 ensemble. Titik awal yang diberikan pada setiap lintasan $u(0)=0, v(0)=0$, dan $w(0)=0$. Gambar 3 sampai Gambar 5 adalah hasil simulasi estimasi gerak surge, sway dan heave pada AUV, dimana gerak surge adalah gerak maju searah dengan sumbu-x dan gerak sway adalah berbelok ke kiri atau kanan searah dengan sumbu$\mathrm{y}$ dan gerak heave adalah gerak turun naik yang searah sumbu-z Selain itu ditampilkan tabel nilai rata-rata RMSE terdapat pada Tabel 2.

Tabel 2. Perbandingan Nilai RMSE Hasil Simulasi

\begin{tabular}{|c|c|c|c|}
\hline \multirow{2}{*}{} & \multicolumn{3}{|c|}{ Berdasarkan Jumlah Ensemble } \\
\cline { 2 - 4 } & $\mathbf{1 0 0}$ & $\mathbf{2 0 0}$ & $\mathbf{3 0 0}$ \\
\hline Surge & $0.0213 \mathrm{~m} / \mathrm{s}$ & $0.0162 \mathrm{~m} / \mathrm{s}$ & $0.0115 \mathrm{~m} / \mathrm{s}$ \\
Sway & $0.0095 \mathrm{~m} / \mathrm{s}$ & $0.0538 \mathrm{~m} / \mathrm{s}$ & $0.0089 \mathrm{~m} / \mathrm{s}$ \\
Heave & $0.0124 \mathrm{~m} / \mathrm{s}$ & $0.0111 \mathrm{~m} / \mathrm{s}$ & $0.0106 \mathrm{~m} / \mathrm{s}$ \\
\hline Time & $1.218 \mathrm{~s}$ & $3.190 \mathrm{~s}$ & $4.234 \mathrm{~s}$ \\
Simulation & & & \\
\hline
\end{tabular}

Pada Gambar 3, Gambar 4 dan Gambar 5 menunjukkan bahwa implementasi metode EnKF pada persamaan gerak 3-DOF dengan membangkitkan 300 ensemble memiliki error kecepatan yang sangat kecil, dimana error gerak surge, swaydan heave memiliki rata-rata akurasi 99\%. Pada Gambar 2, tampak bahwa estimasi gerak surge memiliki error kecepatan $0.0115 \mathrm{~m} / \mathrm{s}$ dengan tingkat akurasi 99,9\%. Gambar 3 menunjukkan bahwa error yang dihasilkan pada gerak sway sangat kecil sehingga antara hasil estimasi dan real hampir sama dengan tingkat akurasi $99.5 \%$. tanda minus pada gerak sway menunjukan bahwa AUV bergerak ke kiri. Gambar
4 merepresentasikan hasil estimasi gerak heave yang hampir sama dengan real. Dengan error kecepatan $0.0106 \mathrm{~m} / \mathrm{s}$ dengan akurasi 99,7\%.

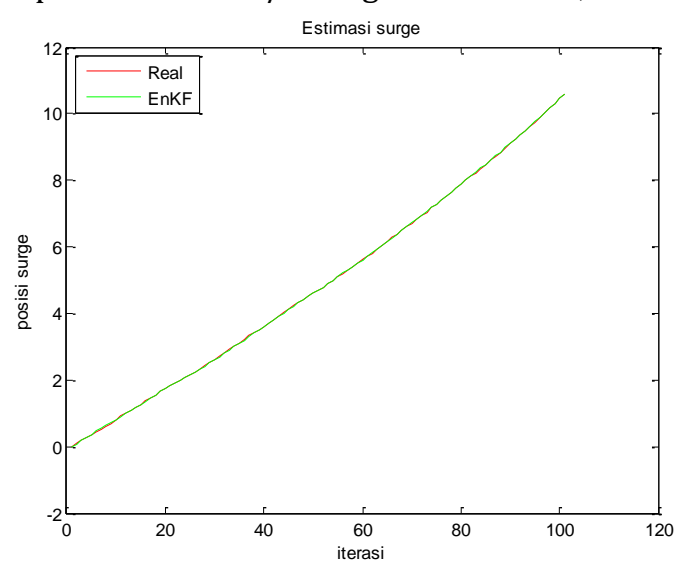

Gambar 3. Estimasi Surge dengan membangkitkan 300 Ensemble

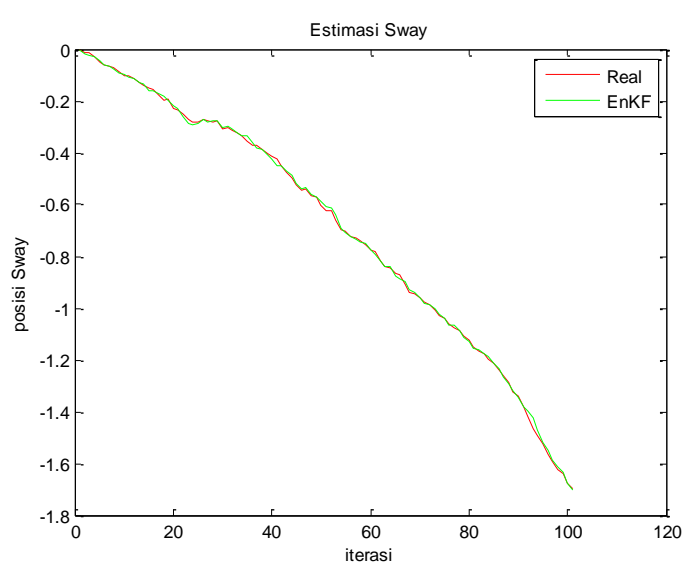

Gambar 4. Estimasi Sway dengan membangkitkan 300 Ensemble

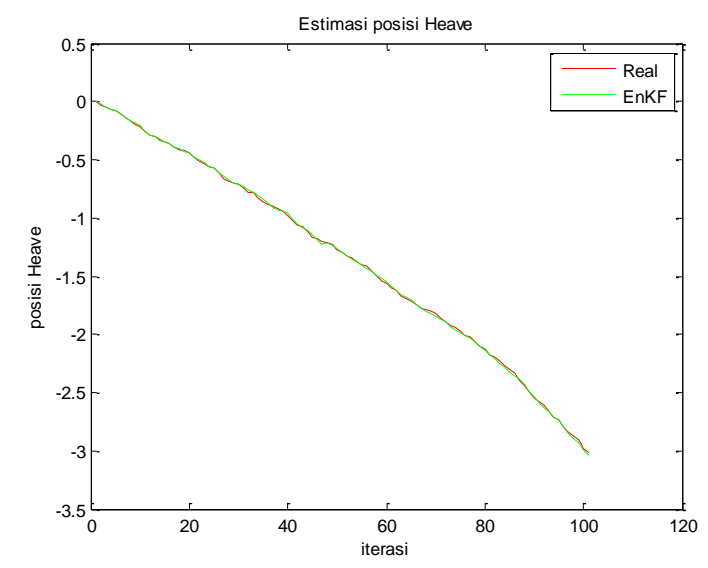

Gambar 5. Estimasi Heave dengan membangkitkan 300 Ensemble

Selanjutnya perbandingan hasil estimasi dengan membangkitkan 100, 200 dan 300 ensemble pada Tabel 2 menunjukkan bahwa dengan membangkitkan 300 ensemble lebih akurat daripada 100 dan 200 ensemble. Dari segi waktu simulasi, dengan membangkitkan 300 ensemble 
memiliki waktu lebih lambat daripada 100 dan 200 ensemble karena jumlah ensemble yang dibangkitkan lebih besar.

Dari hasil analisa pada simulasi dengan membangkitkan 100, 200 dan 300 ensemble didapatkan memiliki error kecepatan yang kurang dari 2\%, sehingga metode EnKF dapat digunakan sebagai salah satu metode estimasi kecepatan gerak Autonomous Underwater Vehicle (AUV).

\section{PENUTUP}

Berdasarkan hasil analisa tentang hasil simulasi metode Ensemble Kalman Filter (EnKF) pada model gerak translasi 3-DOF pada AUV didapatkan bahwa estimasi gerak translasi untuk surge, sway dan heave memiliki tingkat akurasi yang cukup tinggi sekiar 99\% dengan error kecepatan kurang lebih 2\%. Sehingga metode EnKF dapat digunakan sebagai estimator dari gerak translasi Autonomous Underwater Vehicle (AUV).

\section{UCAPAN TERIMA KASIH}

Penulis mengucapkan Terima Kasih Kementerian Riset, Teknologi dan Pendidikan Tinggi (Kemenristekdikti) yang telah mendukung penelitian penulis pada tahun 2018. Peneliti juga mengucapkan Terima Kasih kepada Pusat Unggulan Mechatronics Indutri Automation (PUIMIA-RC ITS) dan Laboratorium Robotika ITS.

\section{DAFTAR PUSTAKA}

An, P. E., Healey, A. J., Park, J., \& Smith, S. M. (1997). Asynchronous data fusion for AUV navigation via heuristic fuzzy filtering techniques. Oceans '97 Mts/Ieee Conference Proceedings, Vols 1 and 2, 397-402\r1510. https://doi.org/10.1109/OCEANS.1997.634 396

Ermayanti, Z., Apriliani, E., Nurhadi, H., \& Herlambang, T. (2016). Estimate and control position autonomous Underwater Vehicle based on determined trajectory using Fuzzy Kalman Filter method. In ICAMIMIA 2015 International Conference on Advanced Mechatronics, Intelligent Manufacture, and Industrial Automation, Proceeding - In conjunction with Industrial Mechatronics and Automation Exhibition, IMAE. https://doi.org/10.1109/ICAMIMIA.2015.75 08022

Herlambang, T. (2017a). Desain Sistem Kendali Gerak Surge , Sway Dan Yaw Pada Autonomous Underwater Vehicle Dengan
Metode Sliding Mode Control ( Smc ), 51-60. Herlambang, T. (2017b). Design of a Navigation and Guidance System of Missile with Trajectory Estimation Using Ensemble Kalman Filter Square Root ( EnKF-SR ). In Computer Applications and Information Processing Technology (CAIPT), 2017 4th International Conference on (pp. 1-7). IEEE.

Herlambang, T., Djatmiko, E. B., \& Nurhadi, H. (2015). Ensemble kalman filter with a square root scheme (EnKF-SR) for trajectory estimation of AUV SEGOROGENI ITS. International Review of Mechanical Engineering, $9(6)$. https://doi.org/10.15866/ireme.v9i6.6341

Herlambang, T., Djatmiko, E. B., \& Nurhadi, H. (2016). Navigation and guidance control system of AUV with trajectory estimation of linear modelling. In ICAMIMIA 2015 International Conference on Advanced Mechatronics, Intelligent Manufacture, and Industrial Automation, Proceeding - In conjunction with Industrial Mechatronics and Automation Exhibition, IMAE. https://doi.org/10.1109/ICAMIMIA.2015.75 08028

Herlambang, T., Mufarrikoh, Z., Karya, D. F., \& Rahmalia, D. (2018). Estimation of water level and steam temperature using ensemble Kalman filter square root (EnKF-SR). In Journal of Physics: Conference Series (Vol. 1008). https://doi.org/10.1088/17426596/1008/1/012026

Herlambang, T., \& Nurhadi, H. (2017). Design of a Sliding PID Controller for The Surge and Roll Motion Control of UNUSAITS AUV, 3(2), 6164.

Herlambang, T., Nurhadi, H., \& Subchan. (2014). Preliminary numerical study on designing navigation and stability control systems for ITS AUV. Applied Mechanics and Materials (Vol. 493). https://doi.org/10.4028/www.scientific.net /AMM.493.420

Kondo, H., \& Ura, T. (2004). Navigation of an AUV for investigation of underwater structures. Control Engineering Practice, 12(12 SPEC. ISS.), 1551-1559. https://doi.org/10.1016/j.conengprac.2003. 12.005

Loebis, D., Sutton, R., Chudley, J., \& Naeem, W. (2004). Adaptive tuning of a Kalman filter via fuzzy logic for an intelligent AUV navigation system. Control Engineering Practice, 12(12 SPEC. ISS.), 1531-1539. https://doi.org/10.1016/j.conengprac.2003. 11.008

Oktafianto, K., Herlambang, T., Mardlijah, \& Nurhadi, H. (2016). Design of Autonomous 
Underwater Vehicle motion control using Sliding Mode Control method. In ICAMIMIA 2015 - International Conference on Advanced Mechatronics, Intelligent Manufacture, and Industrial Automation, Proceeding - In conjunction with Industrial Mechatronics and Automation Exhibition, IMAE. https://doi.org/10.1109/ICAMIMIA.2015.75 08023

Repoulias, F., \& Papadopoulos, E. (2007). Three Dimensional Trajectory Control of Underactuated AUVs. Control, 3492-3499.
Sukarjadi, Arifiyanto, Setiawan, D. T., \& Hatta, M. (2017). Perancangan dan Pembuatan Smart Trash Bin di Universitas Maarif Hasyim Latif. Teknika : Engineering and Sains Journal, 1(2), 101-110.

https://doi.org/10.5281/zenodo.1116487 
T Herlambang, dkk / Teknika : Engineering and Sains Journal, Vol. 2, No.1, Juni 2018, 41-46

Halaman ini sengaja dikosongkan 